\title{
Detecção de predadores naturais das larvas de Simulium fulvinotum Cerq. e Mello, 1968 (Diptera, Nematocera) $\left({ }^{*}\right)$
}

\author{
I. S. Gorayeb $=\Rightarrow$ \\ R. R. Pinger $\# \Rightarrow \Rightarrow$
}

\section{Resumo}

Como a primeira pesquisa sobre estudos ecológicos nos criadouros naturais de simulídeos no Brasil, este trabalho, realizado nas imediações da cidade de Manaus, Estado do Amazonas, objetivou detectar os predadores naturais das larvas de Simulium fulvinotum através dos testes sorológicos de precipitação em tubos capilares (teste não específico para S. fulvinotum) e imunodifusão em agar-gel, aliados às observaçóes de restos larvais de $\mathbf{S}$. fulvinotum nos intestinos dos predadores suspeitos. Larvas de espécies do gênero Macronema (Hydropsychidae) e de Lepidoptera (Nymphulinae, Pyralidae) forcm incriminadas pela primeira vez como predadores de simulídeos. Náiades de Libellulidae (Odonata), Perlidae (Plecoptera) e larvas de Corydalidae (Neuroptera) também foram incriminadas como predadoras das larvas de $\mathbf{S}$. fulvinotum em seus criadouros naturais.

\section{INTRODUÇ.̃̃o}

Os Simuliidae são dípteros importantes pois, além de serem considerados insetos incômodos por sua insistência em atacar o homem e outros animais, são transmissores de doenças. São incriminados como vetores de Onchocerca volvulus Leuckart (Blacklock. 1926), Mansonella ozzardi Manson (Cerqueira, 1959; Shelley \& Shelley, 1976) e causadores iniciais da Síndrome Hemorrágica de Altamira (Pinheiro et al., 1974).

No Brasil na Amazônia, o Simulium amazonicum Goeldi, 1905 tem sido incriminado como transmissor de $O$. volvulus por Rassi et al. (1975), de M. ozzardi por Cerqueira (1959) e como causador inicial da Síndrome Hemorrágica de Altamira por Pinheiro et al. (1974).

O Simulium fulvinotum Cerq. e Mello (1968) apesar de nunca ter sido citado como tendo alguma importância médica ou veterinária, é uma espécie bastante comum nas imediações da cidade de Manaus (Estado do Amazonas, Brasil) apresentando criadouros definidos e restritos a condições ecológicas es. peciais. Esta espécie foi escolhida como um modelo para este primeiro estudo do relacionamento presa-predador nos criadouros naturais de simulídeos no Brasil.

Métodos sorológicos usados no estudo do relacionamento presa-predador, foram aplicados para a detecção dos predadores das larvas de S. fulvinotum. Boreham \& Ohiagu, 1978 apresentaram uma revisão do uso da sorologia no estudo do relacionamento presa-predador em invertebrados. O método de precipitação em tubos capilares, mais comumente usado em entomologia e o método de imunodifusão em agar-gel, menos usado, foram esco. Ihidos. As técnicas sorológicas são valiosos artifícios disponíveis às descobertas no campo da ecologia dos insetos e apresentam vantagens, porque a intensidade da predação ocorrendo na natureza é mensurada.

Este trabalho objetivou detectar os predadores naturais das larvas de $S$. fulvinotum em seus criadouros naturais, que posteriormente possam ser testados e utilizados no possível controle dos problemas que os simulídeos causam ou poderão vir a causar no Brasil e espe. cialmente na Amazônia.

\section{Material e método}

A área de estudo está localizada em uma região de mata com árvores de aproximadamente $15 \mathrm{~m}$ de altura, próxima do campus de experimentos da EMBRAPA (Empresa Brasileira de Pesquisas Agropecuárias) no quilômetro

\footnotetext{
(*) - Parte de um trabalho submetido pelo primeiro autor à Universidade Federal do Estado do Amazonas e Instituto Nacional de Pesquisas da Amazônia, para obtenção do grau de Magister Scientiae.

(“) - Instituto Nacional de Pesquisas da Amazônia, Manaus.

(*..) - Ball State University, Dept. of Physiology and Health Science - Muncie, Indiana 47306 - USA.
} 
30 da rodovia AM-010, Município de Manaus, Estado do Amazonas, Brasil. Dois igarapés de águas pretas correm no local. O primeiro atravessa um pequeno rochedo, corre sobre leito pedregoso, para em seguida passar por uma clareira. O segundo corre sob a mata, passa por cima de uma rocha e cai em cachoeira formando um lago. Os dois igarapés se enquadram como "jovens" na classificação de Dalmat (1955) .

Considerando que as larvas de S. fulvinotum foram encontradas em sua grande maioria fixadas a pedras onde a correnteza é mais acentuada, dois locais foram escolhidos para as observaçōes e coletas: no primeiro igarapé, onde existe uma queda d'água de aproximadamente um metro de altura e no segundo, onde existe uma queda d'água de mais ou menos 3 metros de altura. $\mathrm{O}$ primeiro criadouro tinha águas com pH 4,7 , temperatura média de $25^{\circ} \mathrm{C}$, apresentou uma taxa de oxigênio de $97 \%$, velocidade de $52 \mathrm{~cm} / \mathrm{s}$, condutividade elétrica de $10,8 \mu \mathrm{S} / \mathrm{cm}$ a $20^{\circ} \mathrm{C}(14,7 \mathrm{mg}$ de sais dissolvidos por litro), largura de $1,53 \mathrm{~m}$, profundidade de $22 \mathrm{~cm}$ e vasão de $31 \mathrm{l} / \mathrm{s}$. O segundo criadouro tinha águas com $\mathrm{pH} 4,9$, temperatura de $25,5^{\circ} \mathrm{C}$, apresentou uma taxa de oxigênio de $85 \%$, velocidade de $52 \mathrm{~cm} / \mathrm{s}$, condutividade elétrica de $8,6 \mu \mathrm{S} / \mathrm{cm}$ à $20^{\circ} \mathrm{C}(11,8 \mathrm{mg}$ de sais dissolvidos por litro), largura de $5 \mathrm{~m}$, profundidade de $25 \mathrm{~cm}$ e vasão de $173 \mathrm{l} / \mathrm{s}$ (1).

Utilizando-se uma técnica adaptada de Frank (1967), Dempster (1960), Kwapinski (1972), Service (1973a, 1973b, 1973c, 1976) e Service \& Lyle (1975), um antígeno foi preparado com as larvas de S. fulvinotum. Nos criadouros as larvas foram coletadas com a mão e transferidas com uma pinça a um frasco contendo água do igarapé; este frasco foi depositado em uma vasilha de isopor com gelo, para o transporte ao laboratório. Os frascos permaneceram na vasilha com gelo por um tempo máximo de 5 horas. No laboratório as larvas foram transferidas para água destilada, e mantidas por 12 a 18 horas, sem alimento, para evacuação dos intestinos. A água destilada era oxigenada com bombas de ar. No fim do período de jejum, as larvas eram retiradas da água, secadaš sobre papel de filtro, pesadas e cada duas gramas maceradas em $10 \mathrm{ml}$ de solução salina tamponada, $\mathrm{pH}$ 7,39-7,41 (Wellings, 1969), em banho de gelo, para evitar eventuais desnaturações de proteinas. Cianeto de potássio à $10^{-3} \mathrm{M}$ foi adicionado para impedir a possível deposição de melanina do tecido larvar. A mistura foi centrifugada a 3000 r.p.m. por 20 minutos e ao fluído sobrenadante, usado como antígeno, adicionou-se azida sódica na taxa de $0,01 \%$. O antígeno foi separado em porções de $2,5 \mathrm{ml}$ e conservado no congelador à $-15^{\circ} \mathrm{C}$.

Utilizou-se para a preparação dos anti-soros um método adaptado de Frank (1967), Dempster (1960), Service (1973a, 1973b, 1973c, 1976) e Service \& Lyle (1975). Dois coelhos brancos adultos (Oryctolagus cuniculus), da variedade Nova Zelândia, foram utilizados para a preparação dos anti-soros. Em cada coelho foram aplicadas 4 séries de injeções de antígeno, com intervalos de 12 dias entre cada série. Uma série foi composta de $5 \mathrm{ml}$ de antígeno e $0,2 \mathrm{ml}$ de alumem de potássio estéril a 10\% (como substância adjuvante) sendo aplicada a metade da solução em cada coxa do animal. Após a $3^{a}$ e a $4^{a}$ série de injeções, amostras de sangue foram coletadas por sangramento pela veia da orelha, para testar a presença e a titulação de anticorpos no soro. Quando o título de anticorpos foi considerado como eficiente, os coelhos foram sangrados por punção cardíaca. $O$ soro foi separado, misturado com azida sódica num taxa de $0.01 \%$ e conservado na geladeira em lotes de $2 \mathrm{ml}$.

Nos criadouros das larvas de S. fulvinotum os predadores suspeitos foram identificados no momento da coleta. Os não identificados nesse momento levaram um número idêntico ao de um modelo. Após a dissecação os restos dos exemplares foram conservados em álcool $70 \%$ e estocados com o mesmo número de seus respectivos conteúdos intestinais, macerados em papel de filtro, para posterior identificação no laboratório. Procura de restos de larvas e/ou pupas de S. fulvinotum foi feita no ato da dissecação dos conteúdos intestinais dos predadores suspeitos. Os conteúdos in-

(1) - As medidas foram tomadas por Julio Dellome e com unicadas pessoalmente. 
testinais dos exemplares maiores foram macerados em papeis de filtro e os menores macerados inteiros. Papeis de filtro com os maceradores numerados foram conservados em frascos contendo pentóxido de fósforo dessecante, $\mathrm{P}_{2} \mathrm{O}_{5}$.

No laboratório os papeis de filtro com os macerados dos conteúdos intestinais dos predadores suspeitos foram recortados separadamente e cada amostra misturada em pequenos tubos de ensaio com $0,2-0,5 \mathrm{ml}$ de solução salina normal $(0,85 \%)$, conforme o tamanho do macerado e mantida na geladeira a $4^{\circ} \mathrm{C}$ durante a noite. No dia seguinte os tubos foram centrifugados a 3000 r. p. m. por 20 minutos e os sobrenadantes testados contra o anti-soro total de $S$. fulvinotum por dois métodos, precipitação em tubos capilares (PPT) e imunodifusão em agar-gel (ID) .

\section{1 - Precipitação em tubos capilares}

A técnica de precipitação utilizada foi adaptada de Frank (1967), Dempster (1960), Kwapinski (1972), Service (1973a, 1973b, 1973c, 1976) e Service \& Lyle (1975). Tubos capilares de vidro (de $75 \mathrm{~mm}$ de comprimento por 1,1 $1,2 \mathrm{~mm}$ de diâmetro com paredes de 0,18 $0,2 \mathrm{~mm}$ de espessura) foram utilizados para reagir os conteudos intestinais dos predadores suspeitos contra o anti-soro de $S$. fulvinotum. Leituras das reações foram tomadas 1, 2, 12 e 24 horas após a mistura dos componentes.

\section{2 - Imunodifusão em agar-gel}

Esta técnica foi adaptada de Ouchterlony (1948), Crans (1969), Kaufman et al. (1972), Kwapinski (1972) e Crowle (1973). Na placa com agar-gel, as cavidades periféricas foram preenchidas com as soluções dos conteúdos intestinais dos predadores suspeitos e, após duas horas, a cavidade central foi preenchida com o anti-soro de S. fulvinotum. Leituras foram tomadas $24,48,72$ e 96 horas após o preenchimento da cavidade central. Quando bandas ou linhas de precipitação apareceram entre a cavidade central e uma periférica, a reação era considerada positiva (Fig. 1).

Para calcular a especificidade e a sensibilidade dos testes sorológicos utilizados, antí- geno de larvas de $S$. fulvinotum e antígeno de larvas de Culex spp. foram testados contra o anti-soro de larvas de S. fulvinotum, contra o anti-soro de larvas de Culex spp. e contra o soro de um coelho controle (coelho não injetado com antígenos]. Tabela 1.

\section{REsultados}

No teste de PPT o anti-soro de S. fulvinotum reagiu com o antígeno homólogo até a diluição de 1: 1000 e com o antígeno de larvas de Culex spp. até a diluição de 1: 1000. O anti-soro de Culex spp. reagiu com o antígeno homólogo até 1: 1000 e com o antígeno de larvas de S. fulvinotum até 1: 100. Tanto o antígeno de larvas de $S$. fulvinotum a 1: 10 como o de Culex spp. a 1: 1000 apresentaram reações positivas contra o soro do coelho controle (Tabela 1).

No teste de ID o anti-soro de S. fulvinotum reagiu com o antígeno homólogo até a diluição

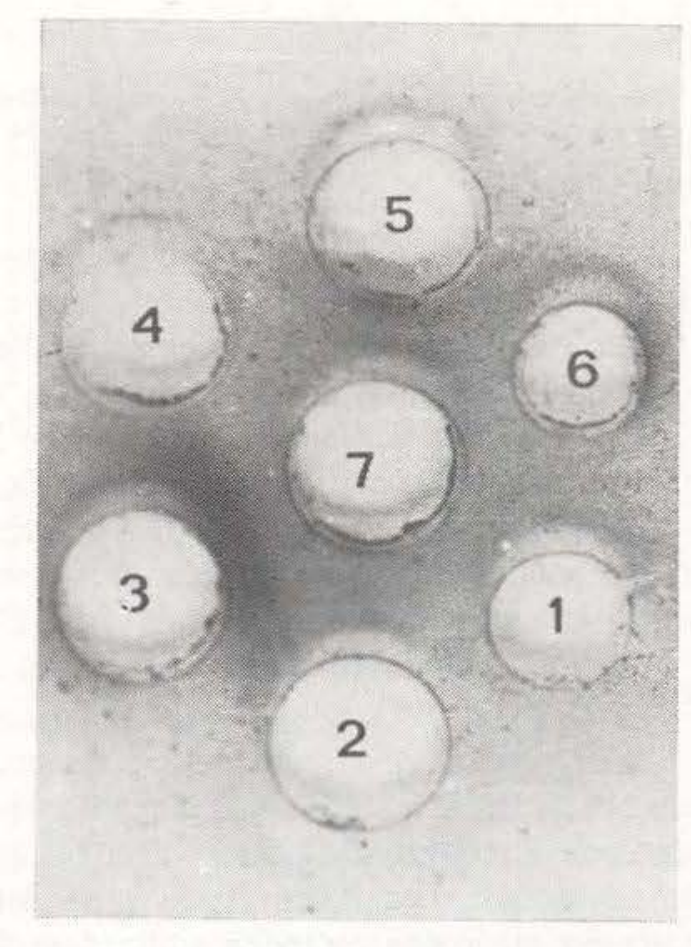

Fig. 1 - Reação positiva de imunodifusão em agar-gel com duas bandas de precipitação entre as cavidades 3 (com solução do conteúdo intestinal de uma larva de Corydalidae) e 7 (com anti-soro de S. fulvinotum). As cavidades $1,2,5$ e 6 continham soluções do conteúdo intestinal de outras larvas de corydalideos. 
TABELA 1 - Precipitação e imunodifusão dos antígenos de S. fulvinotum e de Culex spp., contra os anti-soros homólogos, heterólogos e soro do coelho controle (1).

Precipitação

\begin{tabular}{|c|c|c|c|c|c|c|c|c|c|}
\hline \multirow{2}{*}{\multicolumn{2}{|c|}{$\begin{array}{l}\text { Antigenos } \\
\text { Diluições }\end{array}$}} & \multicolumn{4}{|c|}{ S. fulvinotum } & \multicolumn{4}{|c|}{ Culex spp. } \\
\hline & & Puro & $1 / 10$ & $1 / 100$ & $1 / 1000$ & Puro & $1 / 10$ & $1 / 100$ & $1 / 1000$ \\
\hline Soro o & $\begin{array}{l}\text { As. S. } \\
\text { As. C. } \\
\text { do coelho controle }\end{array}$ & $\begin{array}{l}+++ \\
+ \\
+\end{array}$ & $\begin{array}{l}++ \\
+ \\
\pm\end{array}$ & $\begin{array}{l}+ \\
\pm \\
-\end{array}$ & $\stackrel{+}{-}$ & $\begin{array}{l}++\mathrm{m} \\
+++\mathrm{m} \\
++\mathrm{m}\end{array}$ & $\begin{array}{ll}++ & m \\
++ & m \\
+ & m\end{array}$ & $\begin{array}{l}+ \\
++ \\
+\end{array}$ & $\begin{array}{l}\overrightarrow{+} \\
\pm \\
\pm\end{array}$ \\
\hline
\end{tabular}

Imunodifusão

\begin{tabular}{l|l|l|l|l|l|l|l|l}
\hline $\begin{array}{l}\text { As. S. } \\
\text { As. C. }\end{array}$ & \pm+ & + & - & - & - & - & - & - \\
Soro do coelho controle & - & - & - & - & ++ & ++ & - & - \\
\hline
\end{tabular}

(1) - O soro foi coletado de um coelho controle que năo foi injeta do com antígenos.

As. $\mathrm{S},=$ anti-soro contra larvos de $\mathbf{S}$. fulvinotum.

As, C. $=$ anti-soro contra ladvas de Culex spp.

$+++=$ reação positiva muito forte e evidente.

$++=$ reaçāo positiva forte e evidente.

$+\quad=$ reação positiva evidente. $- \pm=$ reaçăo positiva fraca.

- = reaçấo negativa. $m=$ deposição de melanina do tecído com antígenos.

de 1: 10 e não reagiu com a antígeno de larvas de Culex spp. De forma semelhante o anti-soro de Culex spp. reagiu com o antígero homólogo até 1: 10 e não reagiu com o antígeno de larvas de $S$. fulvinotum. Tanto o antígeno de larvas de S. fulvinotum como o antígeno de Culex spp. não apresentaram reação positiva com o soro do coelho controle (Tabela 1). Outras reações comprovaram que no teste de ID o anti-soro de $S$. fulvinotum reagiu com seu antígeno homólogo até a diluição de 1: 80 .

Nos criadouros das larvas de S. fulvinotum, foram coletados e testados 496 exemplares de predadores suspeitos. Destes, $226(45,5 \%)$ foram detectados positivos como predadores por um ou mais dos métodos utilizados; 221 $(44,5 \%)$ foram positivos pelo teste de ID e $12(2,4 \%)$ por observações intestinais no ato da dissecação (OI). Tabela 2.

As 3 náiades de Libellulidae (Odonata) testadas foram positivas por PPT. Uma foi positiva pelos três métodos (PPT, ID e OI) e neste exemplar foram encontradas 3 larvas de
S. fulvinotum no intestino anterior, antes dos dentes do cibário.

De 46 náiades da família Perlidae (Plecoptera), $27(58,7 \%)$ foram positivas por PPT, nenhuma por ID e $3(6,5 \%)$ positivas por OI. Destas 3, uma com uma larva no intestino anterior, outra com restos e uma larva no intestino anterior e a última com 7 larvas antes dos dentes do cibário.

Das 16 larvas de Corydalidae (Neuroptera) testadas, 10 foram positivas por PPT e uma por por PPT e ID. No intestino anterior desta larva positiva por PPT e ID, foram encontradas 19 larvas de de $S$. fulvinotum e restos de outras larvas de $S$. fulvinotum. No intestino anterior de outro exemplar positivo por PPT foram encontradas 10 larvas de S. fulvinotum. Estas duas larvas de Corydalidae que foram positivas pela presença de larvas de $S$. fulvinotum em seus intestinos, tinham sido mantidas no laboratório em aquários juntamente com larvas de S. fulvinotum. A primeira foi deixada junto com 30 larvas de $S$. fulvinotum e no dia seguinte 
TABELA 2 - Predadores suspeitos das larvas de S. fulvinotum testados por precipitação, imunodifusão e observações intestinais no ato da dissecação.

\begin{tabular}{|c|c|c|c|c|c|}
\hline Ordem - Família - Gênero & N.・ testado & $\begin{array}{l}\text { N.॰ de }+ \text { em } \\
\text { precipitação }\end{array}$ & $\begin{array}{l}\text { N.॰ de }+ \text { em } \\
\text { imunodifusão }\end{array}$ & $\begin{array}{l}\text { Com restos de } \\
\text { S. fulvinotum } \\
\text { nos intestinos }\end{array}$ & Total (") \\
\hline $\begin{array}{l}\text { ODONATA (Náiades) } \\
\text { Libellulidae } \\
\text { Agrionidae }\end{array}$ & $\begin{array}{l}3 \\
1\end{array}$ & $\begin{array}{l}3 \\
1\end{array}$ & $\begin{array}{l}1 \\
0\end{array}$ & $\begin{array}{l}1 \\
0\end{array}$ & $\begin{array}{l}3 \\
1\end{array}$ \\
\hline $\begin{array}{l}\text { PLECOPTERA (Náiades) } \\
\text { Perlidae }\end{array}$ & 46 & $27(58,7 \%)$ & 0 & $3(6,5 \%)$ & $27(58,7 \%)$ \\
\hline $\begin{array}{l}\text { NEUROPTERA (Larvas) } \\
\text { Corydalidae }\end{array}$ & 16 & 11 & 1 & 2 & 11 \\
\hline $\begin{array}{l}\text { COLEOPTERA } \\
\text { Elmidae (Larvas) } \\
\text { Elmidae (Adultos) }\end{array}$ & $\begin{array}{r}3 \\
15\end{array}$ & $\begin{array}{l}1 \\
8\end{array}$ & $\begin{array}{l}0 \\
0\end{array}$ & $\begin{array}{l}0 \\
0\end{array}$ & $\begin{array}{l}1 \\
8\end{array}$ \\
\hline $\begin{array}{l}\text { TRICHOPTERA (Larvas) } \\
\text { Philopotamidae } \\
\text { Chimarra sp. } 1 \\
\text { Chimarra sp. } 2\end{array}$ & $\begin{array}{l}46 \\
11\end{array}$ & $\begin{array}{c}19(41,3 \%) \\
9\end{array}$ & $\begin{array}{l}0 \\
0\end{array}$ & $\begin{array}{l}0 \\
0\end{array}$ & $\begin{array}{l}19(41,3 \%) \\
9\end{array}$ \\
\hline $\begin{array}{l}\text { Hydropsychidae } \\
\text { Macronema spp. }\end{array}$ & 289 & $89(30,8 \%)$ & $6(2,0 \%)$ & $4(1,4 \%)$ & $93(32,9 \%)$ \\
\hline $\begin{array}{l}\text { Helicopsychidae } \\
\text { Odontoceridae }\end{array}$ & $\begin{array}{l}7 \\
1\end{array}$ & $\begin{array}{l}6 \\
1\end{array}$ & $\begin{array}{l}0 \\
0\end{array}$ & $\begin{array}{l}0 \\
0\end{array}$ & $\begin{array}{l}6 \\
1\end{array}$ \\
\hline $\begin{array}{l}\text { LEPIDOPTERA (Larvas) } \\
\text { Pyralidae } \\
\text { Nymphulinae }\end{array}$ & 58 & $46(79,3 \%)$ & 0 & $2(3,4 \%)$ & $47(81,0 \%)$ \\
\hline TOTAL & 496 & $221(44,5 \%)$ & $8(1,6 \%)$ & $12(2,4 \%)$ & $226(45,5 \%)$ \\
\hline
\end{tabular}

(") - Quantidade de predadores incriminados por um ou mais dos métodos utilizados.

OBS.: As porcentagens foram calculadas somente para os grupos que apresentam mais de 30 exemplares.

foram encontradas 19 larvas em seu intestino anterior. A segunda foi deixada junto com 20 larvas e no dia seguinte foram encontradas 10 larvas em seu intestino anterior. A predação ocorreu somente durante a noite.

De 289 larvas de Macronema spp. Burmeister (Hydropsychidae: Trichoptera) $89(30,8 \%)$ foram" positivas por PPT, $6(2,0 \%)$ por ID e $4(1,4 \%)$ por Ol. Dentre estes 4 últimos, um foi considerado positivo pela presença da ca- beça de um $S$. fulvinotum adulto, um pela presença de 3 larvas, outro pela presença da cabeça de uma larva e o outro pela presença de uma larva de $S$. fulvinotum no intestino anterior, sendo que este exemplar também foi positivo por PPT e ID.

De 58 larvas de Nymphulinae (Pyralidae: Lepidoptera) testadas, $46(79,3 \%)$ foram positivas por PPT e nenhuma por ID. Uma foi considerada positiva também pela presença de 
restos de 3 larvas de $S$. fulvinotum nos intestinos. Uma larva de Nymphulinae foi coletada caminhando sobre pupas de $S$. fulvinotum e em seu intestino foram encontrados restos de brânquias de pupas.

De 15 larvas de Elmidae (Coleoptera), 8 foram positivas por PPT; de 3 adultos, somente um foi positivo por PPT.

TABELA 3 - Predadores suspeitos testados por imunodifusão, precipitação e pela presença de restos de larvas de $\mathrm{S}$. fulvinotum em seus conteúdos digestivos.
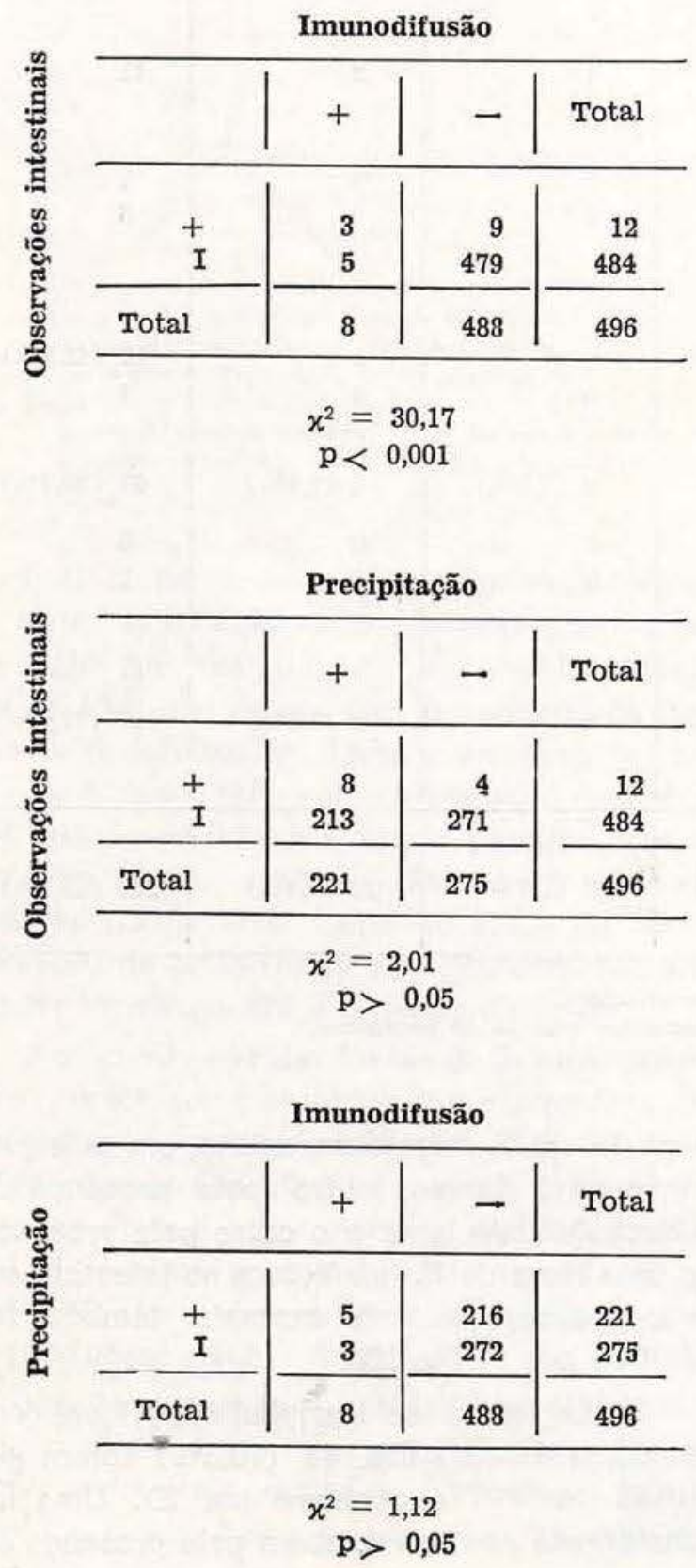

De 46 larvas de Chimarra sp. 1 Stephens (Philopotamidae: Trichoptera), $19(41,3 \%)$ foram positivas por PPT e de 11 larvas de Chimarra sp. 2, nove foram positivas por PPT, porém nenhuma larva de Chimarra foi detectada por ID ou OI.

De 7 larvas de Helichopsychidae (Trichoptera), 6 foram positivas por PPT e nenhuma pelos outros métodos.

Para comprovar associações entre os métodos de detecção de predadores de $S$. fulvinotum, a Tabela 3 apresenta o número de exemplares detectados por cada método em comparação com os outros. Foram calculados valores de $x^{2}$ de cada comparação. Observou-se uma associação estatisticamente significante entre o teste de ID e OI $\left(x^{2}=30,2\right.$; $p<0,001)$. Nenhuma associação foi observada entre os testes de ID e PPT ou entre os testes de PPT e Ol.

Três exemplares foram detectados simultaneamente pelos métodos utilizados: uma náiade de Libellulidae, uma larva de Corydalidae e uma larva de Macronema spp.. Cinco exemplares foram detectados por PPT e OI: três náiades de Perlidae duas larvas de Nymphulinae. Dois foram detectados por PPT e ID: pertencem ao gênero Macronema. Nenhum exemplar foi detectado simultaneamente pelos métodos de ID e OI sem que tenha sido também detectado por PPT.

\section{DISCUSSÃo}

A presente pesquisa emprega o teste de PPT juntamente com o de ID e OI para detectar predadores das larvas de $S$. fulvinotum. O teste de PPT apresentou uma sensibilidade alta, uma titulação de 1: 1000 em relação ao antígeno de $S$. fulvinotum, mas não foi específico, detectando também o antígeno de Culex sp. na diluição de 1: 1000. O teste de ID, ao contrário, apresentou uma sensibilidade de 1: 80 , e foi específico para o antígeno de $S$. fulvinotum. As observações intestinais dos predadores suspeitos (OI) são evidências irrefutáveis da predação, mas somente é possível encontrar restos ou larvas de $S$. fulvinotum nos intesti- 
nos dos predadores poucas horas após a predaçäo, pois eles foram encontrados principalmente antes dos dentes do cibário no intestino anterior do predador e esporadicamente, mais triturados, no intestino médio. A especificidade é mais desejável que a sensibilidade na detecção de predadores, devido à necessidade de se conhecer os principais inimigos naturais de um grupo animal importante que se queira controlar, pois a ação do predador sobre as espécies de presas existentes no criaciouro, se pode conhecer. Assim fica claro, com base neste estudo, que os testes de ID e Ol são mais eficazes na detecção dos predadores, pois são específicos.

Considerando que os testes de ID e OI são eficazes na detecção dos predores naturais das larvas de $S$. fulvinotum, náiades de Libellulidae e Perlidae e larvas de Corydalidae, de Macronema spp. e de Nymphulinae, são incriminadas como predadoras das larvas de $S$. fulvinotum em seus criadouros naturais. Nas listas de predadores de simulídeos apresentada por Jenkins (1964) e Burton \& Mc Rae (1972) não é feita qualquer referência a predadores de simulídeos no Brasil, pois até então não haviam sido realizados no Brasil trabalhos sobre este assunto. Larvas de Trichoptera da familia Hydropsychidae, dos gêneros Hydropsyche Pictet, Smicridea Mc Lachlan, Diplectrona Westwood, Cheumatopsyche Wallengren e Arctopsyche Mc Lachlan eram incluídas naquelas listas como predadores de várias espécies de larvas de simulídeos em outras localidades, mas nenhuma larva de Lepidoptera e do gênero Macronema havia sido citada predando simulídeos. Somente agora este trabalho incrimina as larvas de Macronema spp. e Nymphulinae como novos predadores de larvas de simulideos.

Náiades de Libellulidae também foram incriminadas como predadoras das larvas de $S$. fulvinotum por ID e OI, porém já haviam sido incriminadas como predadoras de simulídeos por Service \& Lyle (1975). Náiades de Plecoptera da familia Perlidae foram detectadas predando larvas de $S$. fulvinotum e Cameron 1922), Crisp (1956) e Wolfe \& Peterson (1959) também detectaram plecópteros predando simulídeos. Larvas de Corydalidae foram incri- minadas e já tinham sido encontradas predando larvas de simulídeos por Twinn (1939) e Daimat (1955) .

Ficou determinado que, nestes experimentos, o teste de PPT não apresentou especıficidade para comprovar predação das larvas de S. fulvinotum, o que não exclui a possibilidade de que os outros grupos de insetos positivos somente no teste de PPT sejam predadores. Uma larva de Agrionidae (Odonata) testada, foi positiva pelo teste de PPT. De três larvas de Elmidae testadas, uma foi positiva por PPT; de 5 adultos, 8 foram positivos. Elmídeos foram coletados associados com as larvas de simulídeos, mas não foram observados predando (Crisp, 1956; Peterson \& Davies, 1960; Peterson, 1960; Service \& Lyle, 1975). Chimarra sp. 1 e Chimarra sp. 2 foram detectadas pelo teste de PPT; as Chimarra já tinham sido incriminadas por Crisp (1956), Peterson (1960), Peterson \& Davies (1960) e Service \& Lyle (1975). Helichopsychidae e Odontoceridae foram positivos pelos testes de PPT como predadores de simulideos, mas não há certeza de que realmente $c$ sejam, pois o teste apresen. tou uma considerável margem de erro.

Observou-se que uma larva de Nymphulinae caminhava sobre pupas de S. fulvinotum; no exame do conteúdo intestinal desta larva, foram encontrados filamentos branquiais das pupas. Outras larvas de Nymphulinae constroem suas teias próximo a aglomerados de pupas. Estas observações podem ser consideradas como evidências da especialização do predador para determinadas fases do desenvolvimento da presa. É provável que haja uma separação de nichos relacionada com as fases do desenvolvimento da presa. Outra observação importante foi a predação, somente durante a noite, por larvas de Corydalidae mantidas no laboratório. Esta observação pode ser uma evidência da provável separação de nichos por períodos de predação. Pode ainda existir uma separação de nichos por um complexo de fatores no qual estes dois estejam incluidos.

A determinação dos predadores das larvas de $S$. fulvinotum é um início dos estudos sobre a relação presa-predador nos criadouros naturais de simulídeos no Brasil. Abre um caminho para estudos deste relacionamento nos criadouros das espécies de importância para o 
homem na Amazônia. O relacionamento presapredador nos criadouros naturais do $S$. amazonicum, que foi incriminado na Amazônia como o transmissor de $O$. volvulus, $M$. ozzardi e causadores iniciais da Síndrome Hemorrágica de Altamira deve ser estudado para um possível futuro controle dos problemas que estes insetos causam ou poderão vir a causar.

\section{AGRADECIMENTOS}

Agradecemos a Dra. Wai Yin Mok pela orientação no uso das técnicas sorológicas. A Maria de Fátima Leite Gorayeb que incentivou este trabalho partilhando passo a passo o seu desenvolver. A Julio Dellome colega do dia a dia da convivência no laboratório. Ao Dr. José Alberto Nunes de Mello por ceder parte de seu laboratório para o desenvolvimento desta pesquisa.

\section{SUMMARY}

As the first attempt on ecological studies on the natural breeding places of black flies in Brazil, this study carried out in the vicinities of the city of Manaus, state of Amazonas, aimed at oetecting the natural predators of the Simulium fulvinotum larvae by means of capillary tube precipitin test (not specific for $\mathrm{S}$. fulvinotum) and agar-gel immunodiffusion test, aided by observations of $\mathbf{S}$. fulvinotum larval remains in the intestines of suspected predators.

Larvae of species of the genera Macronema (Hydropsychidae) and Lepidoptera (Nymphulinae, Pyralidae) were incriminated for the first time as predators of black flies.

Naiads of Libellulidae (Odonata), Perlidae (Plecoptera) and larvae of Corydalidae (Neuroptera) were also incriminated as predators of the $\mathbf{S}$. fulvinotum larvae in their natural breeding places.

\section{BIBLIOGRAFIA CITADA}

BLACKLOCK, D.B.

1926 - The development of Onchocerca volvulus in Simulium damnosum. Ann. tro Med. Parasit., $20: 1-48$.

BOREHAM, P.F.L. \& OHIAGU, C.E.

1978 - The use of serology in evaluating invertebrate prey-predator relationships: a review. Bull, ent. Res., 68 : 171-194.
BURTON, G.J. \& MCRAE, T.M.

1972 - Observation on trichopteran predators of aquatic stages of Simulium damno. sum and other Simulium species in Ghana. J. Med. Ent., 9: 289-294.

CAMERON, A.E.

1922 - The morphology and biology of a Canadian cattle infesting black fly, Simulium simile Mall. (Diptera, Simuliidae). Can. Dept. Agr. N. S., Ent. Bull., $20: 1-26$.

CERQUEIRA, N.L.

1959 - Sobre a transmissão de Mansonella ozzardi. Nota 1 e nota 2. J. Bras. Med., $1: 885-914$.

Cerqueira, N.L. \& Mello, J.A.N.

1968 - Simuliidae da Amazônia. IV) Descrição de Simulium fulvinotum sp.n. (Diptera, Nematocera). Amazoniana, 1: 205-210.

CRANS, W.J.

1969 - An agar-gel diffusion method for the identification of mosquito blood-meals. Mosquito News, $29: 563-566$.

CRISP, G.

1956 - An ephemeral fauna of torrents in the Northern territories of Gold Coast. with special reference to the enemies of Simulium, Ann. trop. Med. Parasit., $50: 260-267$.

CROWLE, A.L.

1973 - Immunodiffusion. 2. ${ }^{\text {a }}$ edi. New York, Academic Press. 545 p.

DALMAT, H.T.

1955 - The black flies (Diptera, Simuliidae) of Guatemala and their role as vector of onchocerciasis. Smithsonian Misc, Collections, $125: 1-425$.

DEMPSTER, J.P.

1960 - A quantitative study of the predators on eggs and larvae of the broom beetle, Phytodecta olivacea Froster, using the precipitin test. J. Amin. Ecol., 29: 149-167.

FrANK, J.H.

1967 - A serological method used in the investigation of the predators of the pupal stages of the winter moth, Operophtera brumata (L.) (Hydriomenidae). Quaest. Ent., 3: 95-105.

JENKINS, D.W.

1964 - Pathogens, parasites and predators of medically important arthropods. Annotated list and bibliography. Bull. Wld. Hith. Org., 30 (Supl.) : 5-150.

Kaufman, L.; Huppert, M.; Netto, C.F.; Pollak, L. \& RESTREPO, A.

1972 - Manual of standardized serodiagnostic procedures for systemic mycoses. Part I: agar immunodiffusion test. PAHO publication : 1-14. 
KWAPINSKI, J.B.G.

1972 - Methodology of immunochemicaì and immunological research. New York. Wilei-Interscience (John Wiley \& Sons, Inc.), $820 \mathrm{p}$.

OUCHTERLONY, O.

1948 - In vitro method for testing toxi-producing capacity of diphtheria bacteria. Acta path. microbiol. scand. 25: 186-191.

Peterson, B.V.

1960 - Notes on some natural enemies of Utah black flies (Diptera: Simuliidae), Can. Ent., $92:$ :266-274.

Peterson, B.V. \& Davies, D.M.

1960 - Observations on some insect predators of black flies (Diptera: Simuliidae) of Algonquim Park, Ontario. Can. J. Zool., $38: 9-18$.

Pinheiro, F.P.; Bensabath, G.; Costa JR., D.; Maroja, O.M.; LINS, Z.C. \& ANDRADE, A.H.P.

1974 - Haemorrhagic Syndrome of Altamira. The Lancet, Apr. $13: 639-642$.

Rassi, E.; lacerda, N.; Guamaraes, J.A.; Vulcano, M.A.; PÉREZ, J.R. \& RAMirez, A.

1975 - Preliminary report on a new vector of onchocerciasis in the Americas: Simulium amazonicum (Goeldi, Lutz, 1910 and 1917). PAHO Bull., 9: 10-12.

SERVICE, M.W.

1973a - Study of the natural predators of Aedes cantans (Meigen) using the precipitin test. J. Med. Entomol., $10: 503-510$. 1973b - Mortalities of larvae of the Anopheles gambiae complex and detection of predators by the precipitin test. Bull. ent. Res., $62: 359-369$.

1973 c - Identification of predators of Anopheles gambiae resting in huts, by the precipitin test. Trans. R. Soc. trop. Med. Hyg., $67: 33-34$.

1976 - Mosquito Ecology. Field Sampling Methods. London. Applied Science Publishers, LTD. $583 \mathrm{p}$.

SERVICE, M.W. \& LYLE, P.

1975 - Detection of the predators of Simulium damnosum by the precipitin test. Ann. trop. Med. Parasit., $69:$ 105-108.

SHElley, A.J. \& SHElley, A,

1976 - Further evidence for the transmission of Mansonella ozzardi by Simulium amazonicum in Brazil. Ann, trop. Med. Perasitol., $70:$ 213-217.

TwINn, C.R.

1939 - Notes on some parasites and predators of black-flies (Simuliidae, Diptera). Can. Ent., $71: 101-105$.

WELLINGS, F.M.

1969 - Epidemiological virological study of the California encefalites group in Trampa Bay of Florida, 1963-1968. Univ. Microfilmi, Inc. Ann, Arbor, Michigan, 140 p.

Wolfe, L.S. \& Peterson, D.G.

1959 - Black flies (Diptera: Simuliidae) of the forest of Quebec. Can. Jour. Zool., 37 : 135-159.

(Aceito para publicação em 19/09/78) 